AIR COMMAND AND STAFF COLLEGE

AIR UNIVERSITY

\title{
INTERNAL BARRIERS TO IMPLEMENTING DIVERSITY MANAGEMENT IN THE AIR FORCE: \\ FOUR CONVERSATIONS WE MUST HAVE
}

\author{
by \\ Debra F. Bean, Major, USAF \\ A Research Report Submitted to the Faculty \\ In Partial Fulfillment of the Graduation Requirements
}

Advisor: Lt Col Royce H. Dasinger

Maxwell Air Force Base, Alabama

April 2000 


\section{Disclaimer}

The views expressed in this academic research paper are those of the author and do not reflect the official policy or position of the US government or the Department of Defense. In accordance with Air Force Instruction 51-303, it is not copyrighted, but is the property of the United States government. 


\section{Contents}

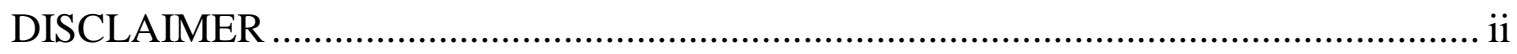

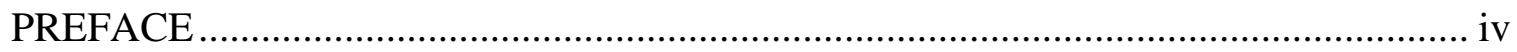

ABSTRACT ...........................................................................................................

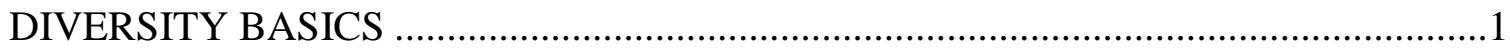

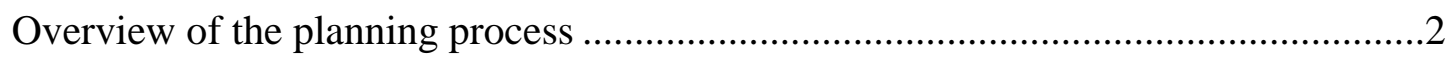

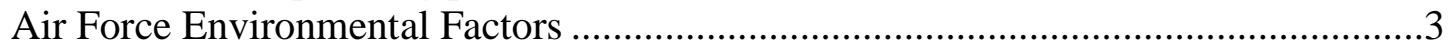

LET'S TALK ABOUT DISCRIMINATION ……………..........................................

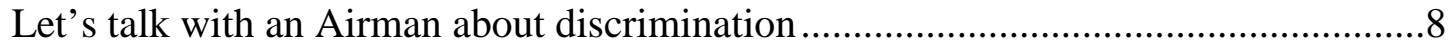

What does this conversation mean to planners? ...................................................... 11

LET'S TALK ABOUT SAMENESS AND DIFFERENCE ............................................15

Let's talk with an Airman about sameness and difference ....................................... 15

What does this conversation mean to planners? ..................................................19

LET'S TALK ABOUT PAST ATTEMPTS TO FIX DISCRIMINATION .......................23

Let's talk with an Airman about past attempts to fix discrimination .........................23

What does this conversation mean to planners? .................................................2

LET'S TALK ABOUT THE LIMITS OF DIVERSITY ...................................................30

Let's talk with an Airman about the limits of diversity............................................30

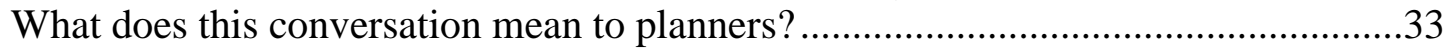

CONCLUSIONS: LET'S TALK ABOUT WHAT'S LEFT TO TALK ABOUT .............37

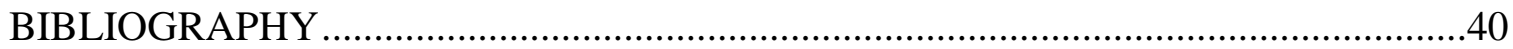




\section{Preface}

Diversity management is not about empathizing or "doing the right thing." While there's nothing wrong with genuine fairness, we can do so much more for the Air Force. Diversity management is about focusing on the essential requirements of our mission, then using a particular set of leadership decisions and skills to ensure that every individual contributes their

best to meeting these requirements. We're not talking equity; we're talking productivity. But this is an approach to productivity that not only achieves the mission, it uplifts the individual. All of us yearn for this kind of leadership, few of us have this kind of skill, but all of us can learn.

As I wrestled with the gray areas and challenges of diversity management, my research advisor, Lt Col "Hank" Dasinger, was incredibly helpful. He helped make tough concepts seem simple and clear, but challenged me not to settle for easy answers. Our conversations about diversity were exhilarating and made my head hurt. They are the impetus for the conversations in this project.

I also want to acknowledge Col Richard P. Packard, the best leader I've ever worked with or observed. As I began to get a theoretical sense of what diversity management entailed, my recollections of his exceptional leadership gave me "real life" examples of what diversity management would look like when implemented. His example reassured me that diversity management was a "doable" and effective approach and challenged me to improve my own leadership to follow his example. 


\begin{abstract}
A number of factors in the Air Force's external environment provide a clear rationale for implementing diversity management. Unfortunately, there is little evidence that the internal environment is as well understood; and this lack of knowledge about barriers and facilitators of change is problematic for program developers.

This project examined one part of internal environmental analysis, the likely barriers to implementing diversity, to provide Air Force planners a set of considerations for effective program development.

A review of literature revealed four common reasons for diversity management failure: 1) Failure to understand and articulate the relationship between discrimination and diversity management, 2) The belief that sameness and difference are mutually exclusive, 3) Failure to understand the legacy of fairness programs, and 4) Failure to create and articulate a valid framework for evaluating which differences should be leveraged and which should be rejected.

Each barrier to implementation is presented as a conversation with a typical airman, to introduce the basic issues. Each conversation is followed by an analysis of the issue for planners, which includes decisions that need to be made in the planning process.
\end{abstract}




\section{Part 1}

\section{Diversity Basics}

Diversity is the widely used label for a variety of programs to improve fairness, access or productivity for legally recognized or perceived minorities. Approaches and terminology for diversity vary widely, but a number of authors describe diversity efforts as being organized around three paradigms. ${ }^{1}$ The first is the discrimination and fairness paradigm. These efforts start with recognition that some demographic groups have been, or are likely to be, discriminated against. Remedies include equal opportunity, fair treatment and compliance with legal mandates, with the goal of increasing representation of legally recognized minority groups in organizations. Fairness efforts focus on processes like recruiting, hiring, development, and promotion programs, with program success judged statistically. ${ }^{2}$ The next paradigm is access and legitimacy. This approach is motivated by recognition that the global marketplace is diverse and successful organizations must be culturally and demographically like their customers to access markets and be legitimate with customers. Organizations operating under this paradigm build a diverse workforce to mirror target customer markets and judge success by market growth, profit and other measures of business success. ${ }^{3}$ A third and evolving approach to diversity is

called many things, but we will use the term diversity management. ${ }^{4}$ Diversity management starts with the premise that the workforce is already diverse, not only in terms of legally recognized minorities, but in terms of a variety of relevant attributes, behaviors and attitudes. 
Diversity management focuses on understanding, accepting and leveraging this diversity to gain the maximum contribution from each individual. Diversity management is measured objectively, in terms of improved organizational productivity. ${ }^{5}$

Ironically, although the number of organizations with diversity initiatives is steadily increasing, the number of discrimination complaints is on the rise. ${ }^{6}$

I don't know of anybody who's satisfied...Almost everybody's angry. To me, that indicates that the diversity initiatives of most companies have been badly mishandled. It's no wonder it's hard to find any fans of employer-sponsored diversity programs. People of color and women feel kind of misled about what changes were going to occur, when in fact almost no changes have occurred in all these years. ${ }^{7}$

The costs of failed diversity initiatives are high: lawsuits, employee turnover, public relations damage, and strained or unproductive work environments. It may be true that doing nothing at all is less costly than embarking on the wrong diversity approach and failing. ${ }^{8}$

Given that failure is costly, it makes sense to plan systematically before implementing a diversity initiative.

\section{Overview of the planning process}

Experts in diversity, strategic planning and organizational change all prescribe similar approaches for planning and executing organizational change. ${ }^{9}$ Successful organizational change starts with a clear understanding of the organization's internal and external environments. Understanding the external environment generally provides the motivation for change. It helps the organization understand why change must take place and what kind of change will be necessary. External environmental factors relevant to diversity management include legal mandates for representation, competitor activities to attract and retain employees, demographic

changes in the labor pool and the work behaviors and expectations of the labor force. ${ }^{10}$ 
Understanding the internal environment also yields motivation for change, but its primary purpose is to clarify the context in which change will take place, to enable effective tailoring of change activities. The internal environment contains forces that press for and against the success of a change effort. These include organizational culture, organizational demographics, past success or failure of similar efforts, management and labor relationships, the attitudes of organization members and senior leader commitment to change. ${ }^{11}$

Dass and Parker explored the relationship between environment and diversity approaches and argue that each of the diversity paradigms has value within particular sets of external circumstances and organizational characteristics. ${ }^{12}$ The value of an approach isn't derived by comparison to other diversity programs but by its appropriateness to the organization's environment and objectives. Likewise, the success of a diversity initiative is as much a function of the integrity with which the organization develops, communicates and implements its program as it is a function of objective measurements like minority representation. "A fit or match among diversity pressures, perspectives, and strategic responses is likely to improve organizational performance, whereas a mismatch is likely to entail economic and noneconomic costs."13

\section{Air Force Environmental Factors}

While the Air Force has a well-institutionalized diversity program based on the fairness and discrimination paradigm, ${ }^{14}$ there are signs of interest in diversity management. ${ }^{15}$ The Air Force's Air Education and Training command has stepped out even further with a number of actions to develop and implement diversity management. If the Air Force wished to implement diversity management across the force, what kinds of environmental information would be available to planners and what would this information reveal about the motivation and context for change? 
Environmental pressures for a shift to diversity management are so widely understood a laundry list will suffice: decreased fiscal resources, increased operations tempo, the challenges of coalition and joint warfare, competition for quality workers, changing demographics in the Air Force and the population we recruit from, the battle to retain airmen and increasing signs of member frustration and diminished morale. The Air Force and the Department of Defense have responded with numerous quality of life and compensation programs to help members and their families live more comfortably and successfully. While all of these actions appear to be on the mark, there is a growing sense that we need to do a better job of understanding, serving, and motivating a military population that is different from the force we've had in the past. ${ }^{16}$

Understanding of internal factors that might affect implementation of diversity management is less robust. There is a lot of information about the internal environment that might be relevant to diversity management planners. Department of Defense Surveys, Air Force Quality of Life surveys, social action unit assessments, Air Force policies, senior leader speeches and policies, diversity working group records and a variety of external assessments of the Air Force all offer insight into the internal environment. However, it doesn't appear the Air Force has officially attempted to "mine" this data to identify cultural or organizational factors that bear on diversity management.

Without internal environment information, diversity management faces two hurdles. First, there is no "one size fits all" diversity end state. Diversity management must be articulated in Air Force-specific ways that are fully supported, clearly communicated and shared at all levels. ${ }^{17}$ This is difficult to do without assessing the Air Force mission, organization and culture. Second, once the end state is defined, it is critical to understand where the Air Force is relative to that 
state. Planning should take into account likely support for, and resistance to, diversity initiatives. ${ }^{18}$ Without this knowledge, it will be difficult build an effective action plan.

This project reviewed diversity literature related to one aspect of the internal environment: barriers to implementation. The purpose was to identify likely barriers, in order to give planners a set of considerations with which to evaluate the Air Force environment and develop a tailored diversity implementation plan. The focus on the negative wasn't coincidental. Diversity management is a relatively new approach and while a few authors offer examples of small organization successes, a frequent assessment is that no large organization has successfully implemented diversity management. ${ }^{19}$ The literature is full of failures and reasons for failures, representing more potential barriers to implementation than can be discussed in this report. However, four reasons for failure emerged repeatedly: 1) Failure to understand and articulate the relationship between discrimination and diversity management, 2) The belief that sameness and difference are mutually exclusive, 3) Failure to understand the legacy of fairness programs, and 4) Failure to create and articulate a valid framework for evaluating which differences should be leveraged and which should be rejected.

This report presents the research findings as "conversations" with an airman who has just learned the Air Force plans to implement diversity management. After this introduction to each barrier, each conversation is followed by an analysis of the issue for planners, which includes considerations that must be addressed in the planning process.

\section{Notes}

${ }^{1}$ David A. Thomas and Robin J. Ely. "Making Differences Matter: A New Paradigm for Managing Diversity," Harvard Business Review 74, no. 5 (September/October 1996); Academic Search Elite, on-line, EBSCOHost, 26 November 1999, n.p. Parshotam Dass and Barbara Parker, "Strategies for Managing Human Resource Diversity: From Resistance to Learning," Academy of Management Executives 13, no 2 (1999): 68-80. Bond, Meg A. and Jean L. Pyle. 


\section{Notes}

"Diversity dilemmas at work," Journal of Management Inquiry 7, no. 3 (September 1998); Academic Search Elite, on-line, EBSCOHost, 14 November 1999, n.p.

${ }^{2}$ Thomas and Ely, n.p., Dass and Parker, 70.

3 Thomas and Ely, n.p., Dass and Parker, 71.

${ }^{4}$ R. Roosevelt Thomas, Jr. and Marjorie I. Woodruff, Building a House for Diversity: How a fable about a Giraffe and an Elephant offers new strategies for today's workforce. (New York: AMACOM, 1999), 1. Dass and Parker (71-72), refer to it as the "learning perspective," Thomas and Ely (n.p.), call it the "learning and effectiveness paradigm." Thomas and Woodruff's "diversity management" is a more descriptive and satisfying wording, because it is closer to business focus of this paradigm-leveraging diversity to improve productivity.

${ }^{5}$ Thomas and Woodruff, 215.

${ }^{6}$ Gillian Flynn, "The harsh reality of diversity programs," Workforce 77, no.12 (1998); Business Management Practices, on-line, FirstSearch, 24 October 1999, n.p. Robert Hartwig, "Truth can Be Stranger Than Fiction in Employment Practices Liability Arena," National Underwriter Property \& Casualty 103, no. 23 (1999); Business Management Practices, on-line, FirstSearch, 24 October 1999, n.p.

${ }^{7}$ Flynn, Harsh Reality, n.p.

${ }^{8}$ Thomas and Ely, n.p.

9 Thomas G. Cummings and Christopher G. Worley, Organization Development and Change, $5^{\text {th }}$ Edition (Minneapolis-St. Paul: West Publishing Company, 1993), 91-93, 495-499. Richard L. Hughes, Robert C Ginnett, and Gordan J. Curphy, Leadership: Enhancing the Lessons of Experience (Boston: Irwin, 1993), 312-338. John A. Pearce II and Richard B. Robinson, Jr., Strategic Management: Formulation, Implementation, and Control, $5^{\text {th }}$ Edition (Burr Ridge, Illinois: Irwin, 1994), 12-19. George T. Milkovich and John W. Boudreau, Human Resource Management, (Homewood: Irwin, 1991), 25-49, 54-65. Dass and Parker, 68.

${ }^{10}$ Dass and Parker, 68. Milkovich and Boudreau, 25-49.

${ }^{11}$ Milkovich and Boudreau, 54-65.

${ }^{12}$ Dass and Parker, 77-79.

${ }^{13}$ Dass and Parker, 68.

14 Air Force Instruction (AFI) 36-2706, Military Equal Opportunity and Treatment Program, Dec 96 and Air Force Pamphlet (AFPAM) 36-2705, Discrimination and Sexual Harassment, Feb 95 describe and communicate the Air Force approach to diversity.

${ }^{15}$ The Honorable Sheila E. Widnall, Secretary of the Air Force, "Setting the Example of Air Force Leadership Through Diversity," address, Strength Through Diversity Conference, United States Air Force Academy, Colorado, April 1995, 6; on-line, Internet, 16 January 2000, available from http://www.af.mil/news/speech/current/Setting_the_Example_of_Air_html. The Honorable Sheila E. Widnall, Secretary of the Air Force, "Defense Advisory Committee on Women in the Service," address, DACOWITS Spring Conference, Vienna, Virginia, 27 April 1995, 5; on-line, Internet, 16 January 2000, available from http://www.af.mil/news/speech/current/Defense_Advisory_Committee.html

${ }^{16}$ Vice Admiral P. A. Tracey, "The Case for Agility-Adapting Military Human Resources to a Changing World," lecture, Air Command and Staff College, Maxwell Air Force Base, Alabama, January 2000. Department of Defense, Armed Forces Equal Opportunity Survey. (Washington, D.C.: Office of the Secretary of Defense, November 1999), on-line. Internet, 


\section{Notes}

Available from http://www.defenselink.mil/news/Nov1999/b112231999_bt544.html, 26 November 1999. Department of Defense, Career progression of Minority and Women Officers, (Washington, D. C.: Office of the Under Secretary of Defense [Personnel and Readiness], November 1999), On-line. Available from http://www.dticaw.dtic.mil/prhome/careerprog.html, Internet, 26 November 1999.

17 Patricia Digh, "Coming to terms with diversity," HRMagazine 43, no. 12 (1998): 117118.

${ }^{18}$ Pearce and Robinson, 173-194. Hughes, Ginnett, and Curphy, 330-336.

19 Flynn, Harsh Reality, n.p., Catalystwomen.org. "Women of Color Report a "Concrete Ceiling' Barring Their Advancement.” Internet, 21 November 1999. Available from http://www.catalystwomen.org/press/mediakit/release071399woc.html. Anne Fisher, "Are you being held back by discrimination?" Fortune 140, no.4 (16 August 1999): 186; Academic Search Elite, on-line. EBSCOHost, 14 November 1999. Anna Smith, "Gender Defender," Management 46, no. 4 (May 1999): 20-22; Academic Search Elite, on-line, EBSCOHost, 19 March 2000. 


\title{
Part 2
}

\section{Let's Talk About Discrimination}

\section{Let's talk with an Airman about discrimination}

\begin{abstract}
Airman: Why do we need diversity management? The Air Force is already a model social institution--better than the civilian world.

Researcher: The military, especially the Air Force, has done a great job of reducing illegal discrimination, but we're not perfect. The recent DOD Equal Opportunity Survey indicates that over $80 \%$ of military members believe the military is as good or better than the civilian world in terms of social conditions. ${ }^{1}$ Unfortunately, this same survey indicated that over 60 percent of members or their families had "experiences ranging from being subjected to insensitive language to physical assault because of their race/ethnicity." ${ }^{2}$
\end{abstract}

Beyond this, organizations with strong fairness cultures like the Air Force are often victims of their own success. ${ }^{3}$ While fairness policies make blatant discrimination unacceptable, they do little to change the underlying biases that lead to discrimination. What you end up with is individuals proclaiming that discrimination doesn't exist, while consciously or unconsciously engaging in subtle discriminatory behavior. "What is often expressed is a subtle racism and sexism communicated through eye contact, who is credited with good ideas and good work, how company celebrations are framed, where and when important decisions are made, and what stated points of view are actually acted on." 5 This might account for an interesting feature of the 
DOD survey, which was that white military members consistently reported better conditions and more optimistic perceptions than did minority members. ${ }^{6}$

Airman: OK, you've convinced me we still need to watch out for discrimination, but that's what Social Actions and Equal Employment Opportunity programs are for. As long as they make good progress, we don't need another program to tell us to treat people fairly.

Researcher: Even the best fairness programs don't do enough to improve organizational productivity; that's the goal of diversity management. While fairness programs consider legally recognized differences, diversity management considers all differences that impact mission accomplishment. Fairness programs ensure people with recognized differences get a fair share of opportunities, but don't necessarily ensure the organization or the individual makes the most of these opportunities. ${ }^{7}$ Diversity management focuses on figuring out how each individual's differences affect mission accomplishment so the organization can use these differences to best advantage. The Air Force shouldn't eliminate fairness programs, but the demands of our environment require we do a lot more to maximize the contributions of every airman.

Airman: So you're telling me that we would need diversity management even if we eliminated illegal discrimination?

Researcher: Exactly, because diversity management is focused on improving productivity. It's a way of leading and supervising to maximize the contributions of every individual, no matter what their differences. The Air Force has always stressed good leadership ${ }^{8}$ as the means to achieving fairness. We want to go beyond fairness and use our good leadership to leverage the diversity of background, values and work styles in the Air Force.

Airman: But if we still have discrimination in the Air Force, how can you say you want to ignore that and leverage differences for productivity? It sounds hypocritical and cynical to me. 
Researcher: You're right, it is hypocritical to teach diversity management and act like discrimination doesn't exist. More importantly, there is an important link between diversity management and discrimination. The basis of diversity management is recognizing individual differences and learning to accept and respect those differences rather than judging them negatively. Some of these differences are the same as those protected from illegal discrimination: race, gender, nationality and so on. More importantly, the same mental processes that lead us to illegal discrimination also lead us to judge people with other differences negatively. ${ }^{9}$ So, if we can be honest about this painful subject it will be very helpful. For example, if we can talk about why we are prejudiced against African-Americans and how this turns into discrimination, it might help us understand how we are insensitive to the needs of single-parents or new recruits. ${ }^{10}$

Now, once we've thought about discrimination, the real work of diversity management begins. It's not enough to say, "I can see that you are different and I won't do anything negative to you because of it." That's fairness. An expert diversity manager would say, "I understand how you are different, I respect that difference because it's an important part of you and I want you to contribute to the mission in a way that is true to what you are."11

Airman: That's a little mushy. Can you give me an example?

Researcher: Sure. Say you have an older civilian on your team. He's very knowledgeable and can do the job with his eyes closed. But he just won't get with the $21^{\text {st }}$ century! He won't use e-mail, hardly even uses the phone. He insists on talking to people face to face and spends his time traveling all over the base to get things done. He's never in the office and when you try to have a quick conversation with him he wants to chat forever. He makes you nuts! 
You would never discriminate against this person. In fact, you write glowing performance appraisals and put him in for awards. But he's such an old geezer-the best way you can think of working with him is to politely ignore him when he rambles on. You also try to be very firm and specific when you give him a task, stressing the need to avoid wasting time gabbing.

You haven't done anything wrong, but are you getting the best performance you can from him? Do you think he's happy being blown off and micro-managed like a child? A good diversity manager would say to this older man, "I see that your experience makes you value personal interaction. The personal relationships you've built are a huge asset to our team and we need to capitalize on your people skills." Instead of asking him to work like the rest of the team the diversity manager tells him to keep doing what he's good at and assigns him tasks requiring personal involvement. He might even be asked to take the younger troops with him so they can meet his contacts and see him in action. This brings an additional set of skills to the team and shows that you understand and respect what is unique about this person. This should improve the productivity of the whole team as well as make him happier about his work.

Airman: You know, I'm the only guy in my shop that really understands technology. We could get so much more work done if they'd only listen to my ideas for using our computers more effectively. But I'm just the opposite of the old guy in your example. They won't listen to me because I'm only 19 and an Airman Basic. We've got nothing in common--they just call me the "Gen X slacker" and laugh me off. I think I understand what you're trying to tell me.

\section{What does this conversation mean to planners?}

This conversation is about two critical related issues: dealing with the presence of discrimination in the Air Force and establishing the relationship of diversity management to existing diversity programs. 
In developing a diversity initiative, some diversity planners try to distance themselves from discrimination, both philosophically and programmatically. ${ }^{12}$ In part this comes from a legitimate application of diversity management principles. The thinking is, "Since diversity management focuses beyond legal fairness and equality, why dwell on discrimination?" Some of the distance is less legitimate. Leaving out the issue of discrimination makes diversity management less threatening to the majority leadership of the organization, whose support is critical to success. Sometimes discrimination is ignored because it is simply too painful to deal with. $^{13}$

However, diversity management programs that don't acknowledge discrimination face significant barriers and likely failure. ${ }^{14}$ Minority airman may view diversity management with mistrust or fear, thinking it's a signal the Air Force is backing away from its commitment to fairness. Majority airmen are likely to downplay the presence of discrimination and wonder what all the fuss is about or assume that they don't need to be as vigilant about ensuring fairness as long as they play along with the new program. ${ }^{15}$

Failing to acknowledge discrimination also robs diversity management of a powerful force for success. Talking about discrimination has two benefits for diversity management. First, illegal discrimination and poor diversity management share the same underlying process of negatively judging people who are different. Understanding why, how, and against whom we illegally discriminate will give us insight into the ways we fail to get the most out of diverse airmen. Second, diversity management requires a leader to deal with one individual at a time; understanding and respecting the background, values, and style of the person, then deciding how to use individual strengths to best advantage. It would be difficult to say, "I respect your values and experience," to an African American man, while refusing to address the discrimination 
which might be a significant part of his life experience. More importantly, a leader who does find a way to talk through what discrimination means to the individual will be able to establish trust and credibility for other diversity decisions and help the entire team gain understanding. ${ }^{16}$

\section{Notes}

${ }^{1}$ DoD Equal Opportunity Survey, n.p.

${ }^{2}$ DoD Equal Opportunity Survey, n.p. All races reported this experience, including White members (63\%). Among minorities, $76 \%$ of Blacks, $79 \%$ of Hispanics, $70 \%$ of Asian/Pacific Islander, and $76 \%$ of Native American/Alaska Natives reported. More members said they had experiences of offensive behavior than experiences of threat/harm.

${ }^{3}$ Genevieve Capowski, "Can't see the diversity for all the differences," HR Focus 75, no. 7 (July 1998): 16; Academic Search Elite, on-line, EBSCOHost, 12 November 1999, n.p.

${ }^{4}$ Bond and Pyle, n.p. Lawrence Bobo, "Race, Interests, and Beliefs About Affirmative Action: Unanswered Questions and New Directions," American Behavioral Scientist 41, no. 7 (April 1998); Academic Search Elite, on-line, EBSCOHost, 26 November 1999, n.p.

${ }^{5}$ Bond and Pyle, n.p.

${ }^{6}$ DoD survey, n.p. For instance, when asked to what extent race relations on the installation/ship were good, $69 \%$ of whites said large/very large extent, while only $39 \%$ of Blacks, 53\% of Hispanics, 56\% of Asian/Pacific Islanders, and 54\% of Native Americans/Alaska natives responded this way. Minorities were almost twice as likely to say that relations were good only to a small/moderate extent.

${ }^{7}$ Thomas and Ely, n.p.

${ }^{8}$ As an example consider "Working Relationships" in AFPAM 36-2705, p.18: "Human relations translates to supervisors showing concern for people and acquiring knowledge about and respect for the background, values, goals, needs and skills of subordinates. Good leadership is willing to listen, respond, and demonstrate trust and confidence in each individual's ability to do the job....Supervisors must foster a work environment that is conducive to accomplishing the mission. Treating everyone with respect and dignity is absolutely essential to ensuring everyone is developing and working toward their full potential."

${ }^{9}$ AFPAM 36-2705, 2.

${ }^{10}$ AFPAM 36-2705, 22, Flynn, Harsh Reality, n.p.

${ }^{11}$ Flynn, Harsh Reality, n.p., Thomas and Woodruff, 79, 230.

${ }^{12}$ Bond and Pyle, n.p.

${ }^{13}$ Delyte D. Frost, "Review worst diversity practices to learn from others' mistakes," $H R$ Focus 76, no.3 (April 1999): 11-12; Academic Search Elite, on-line. EBSCOHost, 12 November 1999, n.p.

${ }_{15}^{14}$ Bond and Pyle, n.p.

${ }^{15}$ Bond and Pyle, n.p. Bond and Pyle imply a causal link between the rise of diversity management, the decreased emphasis on enforcement of EEO and AA law, and the presence of some high-visibility discrimination lawsuits. This research didn't attempt to validate the causality. Given the credible body of evidence about the pervasiveness of prejudice and racism in American society, a reasonable position for an organization embarking on diversity 


\section{Notes}

management would be to assume that in the absence of legal, organizational or cultural controls, members might act on these attitudes.

${ }^{16}$ Flynn, Harsh Reality, n.p. 


\section{Part 3}

\section{Let's talk about sameness and difference}

\section{Let's talk with an Airman about sameness and difference}

Airman: In the Air Force we hold everyone to the same high standards; that's real fairness and equality. Diversity will destroy the uniformity that is critical to military effectiveness.

Researcher: A lot of people feel the way you do. Setting and enforcing uniform standards enhances fairness, eases communication and makes it easier for everyone to understand and meet expectations. But I have to chuckle when you say this because I don't see the Air Force as a group of tin soldiers. Think about what the Air Force really is - the maverick breakaway service, brains and ingenuity over brute force, in love with high technology and the future, redefining warfare every time we go out. I just can't imagine us doing our job without airmen who have the vision and passion to go beyond mere uniformity and meeting standards.

Airman: I see what you mean, but we can't have anarchy.

Researcher: You're right and I shouldn't laugh because lots of people think about diversity exactly the way you do-our only choice is sameness or difference. ${ }^{1}$ Both of these approaches miss the mark. Asking everyone to act the same drives out what's essential and unique about people. We may have order, but we don't get the benefit of every individual's experiences, culture and values. Letting everyone act on his or her own individuality preserves the value of 
the individual but doesn't necessarily generate productive results. Neither of these approaches is right and thinking about them as opposites prevents us from finding a way to use a little of both.

Airman: But if we decided to try a mixture of sameness and difference how would you know which one to use when?

Researcher: Well that's an interesting question, but let me ask you another question first. How do you know we don't already have a mixture of sameness and difference?

Airman: Well sure, everybody knows Air Force demographics are diverse.

Researcher: That's one set of differences; physical differences like race, gender, age and ethnicity. But Air Force people differ in other ways: education level, work experience, role in the Air Force, communication style, language, religion and life experience. ${ }^{2}$ If you checked any group of airmen, you'd find each member of the group was different from the others on some of these dimensions and each was the same on some dimensions. We already have a mix of sameness and difference.

The question then, isn't whether to get a diverse mix, but how to make the best use of the mixture we already have. A lot of experts have researched how diverse groups function in the workplace. We know that diverse teams can generate a productive conflict of styles and ideas which produces better results than teams without diversity. We also know that diverse teams can generate divisive conflict that is completely counterproductive. ${ }^{3}$ Whether the conflict is productive or not appears to depend on three things: the nature of the task, the nature of the conflict and leadership. ${ }^{4}$ I'll bet you can figure out what I mean by the nature of the task. Give me an example of a task that's only done one way, that doesn't require a lot of team interaction.

Airman: That sounds like what I do. There's really only one way to fix a telephone. 
Researcher: Exactly. Individual differences don't matter much in this situation. There isn't a Hispanic or single parent's perspective on phone repair; there's just phone repair. In this case, the team should focus on ensuring everyone repairs the phone correctly and efficiently. This kind of task would rely on emphasizing uniformity. Now give me an example of a task that can be done in a variety of ways, where team interaction might be useful.

Airman: Planning a squadron Christmas party. Everybody's got a million ideas about that.

Researcher: Good example. In planning a party it would be useful to have lots of diversity. A mix of men, women, young airmen, experienced senior noncommissioned officers, people who like parties, people who only attend under orders, parents of young children, and others will generate lots of good ideas so you plan a party that appeals to everyone in the unit. Of course, with a diverse team and complicated project, you can expect more conflict than you would see during a phone repair.

Airman: You're right, there were lots of disagreements. Country music or hip hop? Formal or casual dress? Include children or adults only? It was one debate after another.

Researcher: That's what I would expect. Was it a problem?

Airman: I thought it might be, but it didn't turn out that way. The party chairman had this great way of listening to everyone and finding a way to incorporate what they were enthusiastic about, while keeping everything in synch with the rules of engagement the commander had given us. Every once in a while someone would get a little overexcited and make a smart remark about someone else's idea. The chairman would nip that in the bud and ask them to make their case in a way that wasn't so personal. I even saw her after the meeting with a couple of folks, ensuring they smoothed over their disagreement. 
Researcher: Your chairman must be a natural diversity manager. You had a high level of conflict, but it stayed focused on the task. Without this focus, it's possible the meeting would have ended with poor decisions and hurt feelings. In which case, a diverse team wouldn't have been an advantage. The big challenge for a leader is to keep conflict aimed at solving the task problem without letting it get personal. When this happens, diverse teams produce great results. ${ }^{5}$

Airman: How do I know what kinds of teams to build, so I can get this productive kind of diversity? I'll bet you're going to tell me to ensure I have a mix of genders, skin colors, and stuff like that.

Researcher: No I'm not. We don't usually get to choose our teams but the Air Force is already diverse, so you'll have enough useful differences in any team you're on. The key is recognizing and managing those differences. A leader needs to get to know their people and understand their abilities, experiences and style. Without this knowledge a leader can't draw out the best each person has to offer. Once you understand the differences you have to work with it's all in how you manage the team: knowing when to call on diverse viewpoints and when to stick to the rule book, ensuring that conflict stays task and not people-focused.

But let's assume you do get to assemble a team. It's true that two people with different skin color might be very different. They might also be alike in every respect except skin color. You simply can't tell what perspectives and strengths a person brings to the team based on externals. ${ }^{6}$ So a good diversity manager isn't interested in making sure the team looks diverse, he focuses on making sure the team really is diverse.

This gets us back to your question about the "right" kind of diversity. There's no one kind that's right. It depends on three things—can you think what they might be?

Airman: Don't tell me—task, conflict and leadership. 


\section{What does this conversation mean to planners?}

This conversation is about defining the differences that matter and what the organization wants to achieve with diversity. They are possibly the two most important elements of a diversity initiative and are where initiatives are most likely to derail. ${ }^{7}$

There is a tremendous amount of literature regarding individual differences and their effect on workgroup performance. It can be contradictory and confusing but planners can keep the process simple by focusing on two facts. The first fact is that the Air Force doesn't have to "get diverse," our fairness programs and U.S. demographics have already done this job. ${ }^{8}$ What planners must do is understand the kinds of differences that are present and articulate the ones that are important for mission accomplishment. The second fact is that diversity almost always leads to conflict, for good or bad. ${ }^{9}$ The purpose of diversity management isn't to decrease this conflict, but to understand and manage it in ways that increase productivity. ${ }^{10}$

In defining differences that matter, there is a tendency to focus on external differences like race or gender. Indeed, most literature focuses on how these differences affect performance. But there is a growing body of work coming to two related conclusions. The first conclusion is that not all members of a demographic group are the same in terms of behaviors or attitudes. ${ }^{11}$ So a diversity definition that focuses on the presumed behaviors of demographic minorities is likely to be wrong. Furthermore, focusing on the behaviors of demographic groups invariably leads to stereotyping individuals, even to the point of reinforcing negative stereotypes. ${ }^{12}$ The second conclusion is that a host of factors other than demographics may exert influence on workplace

conflict. ${ }^{13}$ Functional role in the organization, communication style, organizational experiences, and upbringing can have huge impact on individual performance and group interaction. ${ }^{14}$ 
For this reason, diversity management definitions tend to be wide and inclusive, along the lines of Thomas' definition of "any combination of individuals who are different in some ways and similar in others."15 This alerts everyone in the organization to the idea that any group of people is a diverse mix to be managed, not just groups that appear to be physically diverse. While a wide definition is both constructively descriptive and simple to communicate, planners need to ensure this doesn't appear to trivialize differences that historically mattered.

Planners must also define the ways in which airmen are similar. ${ }^{16}$ Regardless of the task, groups that share a sense of similarity and purpose will perform better.$^{17}$ In part, our similarities run along the same dimensions as our differences. For example, a black man and a white woman who are both parents have a wealth of experiences in common; parenthood is likely to color a great deal of their life and work experience and be a source of similarity. More critically, planners need to identify similarities in terms of an organizationally-unique set of dimensions. ${ }^{18}$ Examples include values, cultural elements, and shared experiences like deployment. However the Air Force defines it, the diversity definition must include all members. This is a statement of what the Air Force values in its people and each airman must be able to see that he or she is included in the diversity mix. ${ }^{19}$

Having recognized the kinds of diversity that are relevant to mission accomplishment the challenge is how to leverage this diversity. While the concepts really are as simple as they sound in conversation, application is extremely difficult. Diversity management involves abandoning ingrained criteria for sorting and judging people and replacing them with an entirely new system that emphasizes searching out and affirming individual differences in the service of productivity. This isn't likely to come naturally. ${ }^{20}$ 
To facilitate this change, planners must be prepared to engage in a long-term, multi-faceted approach. Certainly, a central piece of the program will be awareness training about diversity concepts and leadership practices. But this is a business program, and training alone won't achieve the desired result. ${ }^{21}$ “...it must be part of an overall strategy that includes specific goals, measurement, skills training and accountability. ${ }^{22}$

\section{Notes}

${ }^{1}$ Bond and Pyle, n.p.

2 Patricia Digh, "Coming to terms with diversity," HRMagazine 43, no. 12 (1998): 118.

${ }^{3}$ Ray Hood-Phillips, "Embracing racial diversity: A matter of survival," Community College Week 11, no. 24 (12 July 1999): 4-5; Academic Search Elite, on-line, EBSCOHost, 14 November 1999, n.p. Karen A. Jehn, Clint Chadwick, et al, "To Agree or not to Agree: The Effects of Value Congruence, Individual Demographic Dissimilarity, and Conflict on Workgroup Outcomes," International Journal of Conflict Management 8, no. 4(October 1997): 287-305, Academic Search Elite, on-line, EBSCOHost, 22 November 1999, n.p.

4 Poppy L. McLeod and Sharon A. Lobel, "Ethnic Diversity and Creativity in Small Groups," Small Group Research 27, no. 2 (May 1996): 248-264; Academic Search Elite, on-line. EBSCOHost, 22 November 1999, n.p. Karen A. Jehn, "A Multimethod Examination of the Benefits and Detriments of Intragroup Conflict," Administrative Science Quarterly 40, no. 2 (June 1995): 256-282; Academic Search Elite, on-line, EBSCOHost, 22 November 1999, n.p.

${ }^{5}$ Jehn and Chadwick, n.p.

${ }^{6}$ Bond and Pyle, n.p.

${ }^{7}$ Digh, 118.

${ }^{8}$ Diversity Training Group, Dynamic Demographics, on-line, Internet, 12 October 1999. Available from http://www.diversitydtg.com/articles/demogs.html.

${ }^{9}$ Lisa H. Pelled and Kathleen M. Eisenhardt, et al, "Exploring the black box: An analysis of work group diversity, conflict, and performance," Administrative Science Quarterly 44, no. 1 (March 1999): 1-28; Academic Search Elite, on-line, EBSCOHost, 24 October 1999, n.p. Jehn and Chadwick, n.p. Jehn, n.p.

10 McLeod and Lobel, n.p. David C. Thomas, "Cultural diversity and work group effectiveness," Journal of Cross-Cultural Psychology 30, no. 2 (March 1999): 242-263; Academic Search Elite, on-line, EBSCOHost, 24 October 1999, n.p.

${ }^{11}$ Ralph A. Rodriguez, "Challenging demographic reductionism," Small Group Research 29, no. 6 (December 1998): 744-758; Business Management Practices, on-line, First Search, 12 November 1999, n.p.

${ }^{12}$ Flynn, Harsh Reality, n.p., offers an example of this approach's outcome, to show trivial and insulting it can be. "Hello, you're Hispanic, I am aware you may not start meetings on time. I value that approach."

${ }^{13}$ Jehn and Chadwick, n.p.

14 Jehn and others tend to distinguish between "good" conflict, which is task-based, and "bad" conflict, which is relationship based. Although not a consensus, it appears that 


\section{Notes}

demographic differences may be at the root of much relationship conflict and that these emerging factors may be the source for good task conflict. This being the case, continued focus on demographics only enables the organization to keep a lid on conflict. Understanding and valuing the differences that generate productive conflict may be the real key to leveraging diversity.

${ }^{15}$ Thomas and Woodruff, 5.

16 Thomas and Woodruff, 15.

17 Jehn, 9

18 Stephen B. Knouse and Mickey R. Dansby, "Percentage of Work-Group Diversity and Work-Group Effectiveness," Journal of Psychology Interdisciplinary and Applied 133, no. 5 (September 1999): 486-494; Business Management Practices, on-line, FirstSearch, 12 November 1999, n.p.

${ }^{19}$ Digh, 119.

${ }^{20}$ Bond and Pyle, n.p., explain US cultural self-image and public policy is largely based on assimilation, the expectation that minorities desire to and will assume the behaviors of the majority. Even in the face of determined resistance by minorities, a large portion of corporate and organizational America still assumes this is a minority desire. DoD Career Progression, n.p., provides ample evidence of the military propensity for assimilation and of female and minority frustration over the pressure to be like the majority. Diversity management is the opposite of assimilation, focusing on nurturing differences to improve productivity, so a shift to diversity management should be characterized as a significant cultural shift for any organization. While this research didn't delve into the issue of facilitating cultural change, the Air Force knows from Total Quality Management implementation just how difficult this kind of strategic change can be.

${ }^{21}$ Flynn, Harsh Reality, n.p.

${ }^{22}$ Frost, n.p. 


\section{Part 4}

\section{Let's talk about past attempts to fix discrimination}

\section{Let's talk with an Airman about past attempts to fix discrimination}

Airman: Diversity management is just another name for Affirmative Action; just a new way of saying that white males must pay for the discrimination of the past.

Researcher: I can see that you are angry about Affirmative Action. I won't debate you about whether Affirmative Action was properly motivated or truly effective in our short conversation, because that's not very important. What's important to me is how your feelings about efforts to reduce discrimination might affect your willingness or ability to implement diversity management. So tell me what makes you angry.

Airman: I'm sick and tired of being blamed for discrimination. ${ }^{1}$ Anti-discrimination programs make it clear I'm the problem, just by the victims they pick. Sexual harassment happens to women, so it must be a guy who does it. People of color are the victims of discrimination, so a white person is the villain. We all know blacks can be racist and women can be harassing. Why am I the only one who gets blamed?

Researcher: Well, you're right to be bothered about this. The fairness paradigm, out of which programs like Affirmative Action emerged, left us with the legacy of a designated majority and designated minorities. Our focus has been on providing opportunities for designated minorities who haven't historically achieved the same success as the white male 
majority. These opportunities were attempts to help minorities "play better" on a white male playing field. The message, right or wrong, that came out of this approach was two-fold: the majority is responsible, if not for the problem, then at least for the solution, and the minority has handicaps which it can't overcome on its own. ${ }^{2}$ Taken to extremes these approaches evolved, at least perceptually, into blaming the white male majority and viewing members of a minority group as needing "fixing." It's hard to tell who is angrier about this message: white males who feel unfairly blamed or minority members who are disgusted about being viewed as weak and not otherwise deserving.

Even if they do no harm, approaches that focus on demographic differences are simply missing the point. White males won't be the majority forever, but intolerance and discrimination will exist anyway. It's the natural tendency of groups in power to set the rules, reinforce the culture and discriminate against those who are different. Focusing only on the current group in power divides the organization into a majority and a minority and prevents us from understanding the real basis of discrimination. We won't be able to see all the other differences that can cause just as much trouble as skin color or gender. For instance, the on-going cultural and professional separation of rated and non-rated airmen might be just as much a challenge for the Air Force as animosity between airman of different races.

Airman: But this isn't even the part that bothers me most. I've got no problem with giving a break to a minority person who's most qualified. That's fair, even if I lose out. But everywhere I turn, it seems like minorities get all the breaks, and some of them aren't as qualified as I am. It looks like reverse discrimination to me. I suppose you think I'm a racist for saying that. Researcher: I don't know you well enough to make a judgement like that. Truth be told, 
most of us think about life in America through the lens of our own position in the racial mix. ${ }^{4}$ Whether that manifests itself in racism or bigotry is something I'll leave for you to figure out. What's really interesting is that you say you "lose out," like it's a competition. Lawrence Bobo found a similar reaction in his Los Angeles County Social Survey. While racism was certainly a part of objections to Affirmative Action, the really powerful objections came from the belief that limited resources (jobs, promotions, power) were being divided up in a zero sum process. There was a sense that this process had been stacked in favor of minorities and that decision-making was based on minority status and not on competence. ${ }^{5}$

\section{Airman: That's what I'm saying.}

Researcher: What's funny is that minority support for Affirmative Action comes out of the same belief. They too see the world as win-lose, only they've historically been the losers. They perceive the process is stacked in favor of the majority and that decision-making is based on majority status and not on competence. ${ }^{6}$ Maybe the real problem is that somebody has to lose and whoever has power controls the process for selecting winners and losers. This being the case, those in power will fight hard to keep it and those out of power are vulnerable. As the U.S. population changes and white males become one of many minorities, ${ }^{7}$ we might see some interesting flip-flops of attitudes about racism, discrimination and Affirmative Action because of this. ${ }^{8}$ What all this means is that white men have as much of a stake in improving the way we decide who wins and loses as the current minority has.

Airman: So what makes diversity management any different from Affirmative Action?

Researcher: Diversity management tries hard to avoid some of the problems that come out of the win-lose structure. For starters, diversity management doesn't designate a majority, because measuring performance or behavior against a majority group is irrelevant. Every person 
in the organization is simply a member of the diversity mix, with his or her unique collection of attributes. ${ }^{9}$ The two approaches also differ over what to do with someone who is different. In Affirmative Action, the minority requires assistance to gain equal opportunity, which implicitly marks them as weak. In diversity management, no one on the team is inherently weak or strong because every person has a variety of differences from others on the team. Whether these differences are strengths or weaknesses depends on their contribution to, or degradation of, the Air Force's mission requirements. It becomes the job of the supervisor to focus on how to use each person's strengths most productively.

Airman: Fine, but when it comes time to decide who gets the rewards, women and minorities are still going to have the edge aren't they?

Researcher: Not necessarily. For starters, if everyone is respected and has their individual strengths nurtured and valued, then all of us will be competing from the strongest possible position. Hopefully, this will mean that the most capable person will be rewarded and all of us will understand who is most capable and why. The other thing that could happen in diversity management is a slight shift in decision-making. Generally, we decide who is rewarded using the same criteria for all circumstances. We look at things like past performance, exemplification of the whole person concept and how closely the person personifies our ideal warrior/leader model. The effect of this is a propensity to select the same kinds of people all the time. ${ }^{10}$ Diversity managers look at things like promotions and work assignments not only as ways to reward good performance but as tools to shape the diversity of the team.

I'll give you an example. You are the project officer for the annual air show and you have to pick a deputy. The project officer and deputy get all kinds of glory and usually get picked for command in a year or two. The most common choice for deputy is another Major who is a pilot 
like you. But your team already has a lot of pilots on the various committees. When you think about what the project entails you realize you don't need more flying expertise, you need somebody who can do two things you have trouble with: work with the Support Group and get organized administratively. So you select a major out of the communications squadron to be your deputy. You were really impressed with the way she handled the installation of a new network in your squadron. Everybody else was going nuts but she was totally on top of the project. The major happens to be a woman, but that isn't why you picked her. You picked her because her differences added important strengths to the team.

Airman: Oh, I get it. This would be like me getting picked to be the airman-in-charge of my shop, over more senior guys, because I have the best skills at interfacing with our customers. Boy, if I thought that would happen, I'd be all for diversity management.

\section{What does this conversation mean to planners?}

For all its benefits, Affirmative Action generated controversy and backlash that are likely barriers to implementing diversity management. ${ }^{11}$ There is a strong debate in the literature as to whether this backlash is based on racism, principled beliefs about individual responsibility, or anger about losing economic or cultural power. Planners don't need to get mired in this debate because there is a common thread in these objections. All of them are evidence of resistance to change; specifically resistance to a process viewed as competitive and zero sum. ${ }^{12}$

In implementation, Affirmative Action's legacy of majority and minority designation can sneak into diversity management, reinforcing the suspicion of a win-lose change. Many diversity programs focus primarily or solely on differences in the behavior of recognized demographic groups, which tends to divide an organization into two parts--the majority and those who are different. ${ }^{13}$ Having divided the organization, programs take one of two 
approaches. The first is to focus primarily on getting the majority to understand why its culture and behaviors are offensive to the minority members of the organization. In essence this holds the majority responsible for the organization's problems with diversity, which Frederick Lynch refers to as "diversity penance." 14 The other approach focuses on helping minority members see how their diverse behaviors differ from the norm and on how they can adopt behaviors that will be more successful. Special minority mentoring programs are a common application of this approach. ${ }^{15}$ All of these approaches build on the legacy of Affirmative Action, by continuing to compare minority behavior to the majority.

To avoid this barrier, planners must include all airmen in the diversity mix, not just demographic minorities. Program goals must make clear the intention is for all airmen to be more comfortable and productive in the work environment. ${ }^{16}$ Finally, and most critically, success must be judged with productivity or employee satisfaction metrics, not demographic statistics. ${ }^{17}$ Without this, diversity management will deservedly be lumped in with Affirmative Action and resistance will be difficult to overcome. However, taking the focus off statistical measures of fairness can be risky, because the Air Force would lose the strong safety net that fairness programs provide. There could be either the perception or the reality that as long as airmen appear respectful, no one will be held accountable if minority airmen fare poorly.

Diversity management will require on-going training in concepts and application for all airmen. In particular airman must receive the training and tools they need to respond to differences in a way that isn't baselined against a particular power group. As this training is developed and presented, planners must avoid the temptation of assuming that historic minorities understand diversity management any better than the majority. ${ }^{18}$ The common practice in most organizations is to have minority members teach diversity classes. This implicitly, and often 
explicitly, reinforces the message that the majority bears the responsibility for fixing the organization's problems. ${ }^{19}$ Airman must learn about diversity from diverse leaders and trainers.

\section{Notes}

${ }^{1}$ Bond and Pyle, n.p.

${ }^{2}$ Flynn, Harsh Reality, n.p.

3 Frost, n.p. Gregory R. Maio and Victoria M. Esses, "The Social Consequences of Affirmative Action: Deleterious Effects on Perceptions of Groups," Personality and Social Psychology 24, no. 1 (January 1998): 65-74; Academic Search Elite, on-line, EBSCO, 26 November 1999, n.p. Maio and Esses' study concluded that simply knowing a fictitious group of people was eligible for affirmative action produced assumptions that they would be "less competent and less valuable." This propensity was so widespread and unconscious "one might wonder whether affirmative actions harms a group in more ways than it helps..."

${ }^{4}$ Bobo, n.p. Oscar H. Gandy, Jr. and Jonathan Baron, "Inequality: It's All In The Way You Look At It," Communication Research 225, no. 5 (October 1998): 505-525; Academic Search Elite, on-line, EBSCOHost, 26 November 1999, n.p.

${ }^{5}$ Bobo, n.p. Bond and Pyle, n.p., echo this conclusion.

6 Gandy and Baron, n.p.

7 Diversity Training Group, Dynamic Demographics, on-line, internet, 12 October 1999. Available from http://www.diversitydtg.com/articles/demogs.html. By 2050, non-Latino whites will be a bare $52 \%$ majority, with males being less than half of that amount.

${ }^{8}$ Gillian Flynn, "White males see diversity's other side," Workforce 78, no. 2 (February 1999): 52-56; Academic Search Elite, on-line, EBSCOHost, 12 November 1999, n.p.

${ }^{9}$ Thomas and Woodruff, 15.

${ }^{10}$ Bobo, n.p.

${ }^{11}$ Bond and Pyle, n.p.

${ }^{12}$ Bond and Pyle, n.p., Bobo, n.p., Gandy and Baron, n.p.

13 Helen Lippman, "Harnessing the Power of Diversity," Business and Health 17, no. 6 (June 1999); 40.

${ }^{14}$ Flynn, Harsh Reality, n.p.

${ }^{15}$ Frost, n.p.

${ }^{16}$ Flynn, White Males, n.p.

${ }^{17}$ Frost, n.p.

${ }^{18}$ Flynn, Harsh Reality, n.p.

19 Flynn, White Males, n.p. This approach also might also have a nasty unintended consequence, highlighted in the DoD Career Progression of Women and Minority Officers report (n.p.): In addition to falling into the trap of reinforcing the designated majority/minority, selecting women and minorities for training and personnel jobs reinforces stereotypes about their capabilities and the functions for which they are qualified. Since these jobs aren't highly valued by the military, women and minorities who do them tend not to be as highly recognized or promoted. It would be interesting to speculate about the outcome on career progression and diversity management if only white males were responsible for diversity training, or if all members had to pull a "diversity tour" as a part of normal career progression. 


\section{Part 5}

\section{Let's talk about the limits of diversity}

\section{Let's talk with an Airman about the limits of diversity}

Airman: I'm all for respecting the individual but the military mission is unique and can't be performed by everyone. Diversity gurus want us to include everyone in everything and this will destroy the high standards of the Air Force.

Researcher: To the contrary, diversity management isn't about embracing all differences. Thomas says it's about determining the effect of individual differences on mission accomplishment and including or excluding people solely on that basis. ${ }^{1}$ He suggests a simple approach for responding to individual differences: if the difference is necessary for mission accomplishment then respect and maximize the difference. If the difference doesn't have any impact on the mission, then just accept it as a fact. If the difference degrades the mission, then reduce the difference or get rid of the person. ${ }^{2}$

Airman: Well I'm glad to hear that. We all know there are legitimate reasons for excluding people from the active-duty Air Force or from certain missions: for example, physical abilities, gender, sexual preference, or not meeting standards.

Researcher: Just about every organization argues that certain unique abilities, values and attitudes are essential to the organization. Most don't even question these essential elements; they are so well understood and agreed upon they've become a part of the culture. For instance, 
the military has a variety of health and fitness standards that are non-negotiable requirements for membership. We don't embrace the diversity of someone who doesn't meet these standards; we exclude them from service in the active duty force. But, one person's unquestioned requirement is another person's non-essential preference.

Airman: What's that supposed to mean?

Researcher: It means that we haven't always done a good job of thinking about the basis for our non-negotiable requirements. If we can't clearly point to a mission requirement for including or excluding an individual difference, then we're probably just acting on preference. Excluding people who are different because of an organizational or individual preference, no matter how well motivated, is discrimination. For instance, not too long ago, the military services kept African Americans segregated and assigned to less desirable missions. At the time, it was a non-negotiable requirement—we thought black people couldn't perform the same kinds of missions as white people. But we now know that this was really just a preference.

Airman: That's the same lesson we later learned with women in the military.

Researcher: Exactly. But the inclusion of women shows just how tricky this issue is. One of the things the Air Force did when women were integrated into the service was to set up different physical fitness standards for men and women. Now this can be construed as meaning one of two things. Some interpret this to mean that women can't meet the standards. If this is true, and the standard is really non-negotiable, we shouldn't allow women to serve in the military. But what if the change in standards really means that the mission doesn't require the absolute level of fitness we always thought it did, so it was okay to have a different standard for women? If this is true maybe we need to change the standards for men too! My point is not that we need to revisit the integration of women in the military. It is that we need to review all the 
written and unwritten standards we've declared nonnegotiable, ensure they have a clear mission basis, then apply them equally to all members of the organization.

But before we rush to reaffirm our nonnegotiable standards we need to make sure they really aren't negotiable. The military in particular has a lot of behaviors that are important to us culturally, but not really mission requirements. Without a clear understanding about the difference between culture and mission, and consistent application of requirements, we will always be open to accusations of unfairness and some of our people will appear to have received special treatment. This will make diversity management impossible.

Airman: Well you're preaching to choir about women in the military. I'm all for putting women in every role, even the combat missions.

Researcher: I'm glad to see that you're open minded, but it's important to remember that diversity management isn't about getting every minority represented in every facet of the organization. The goal is to maximize the right kinds of diversity for the right kinds of missions. For instance, if you've been shot down, you want the strongest, toughest airmen in the force to fish you out of the ocean. You don't want a woman who's not physically up to the challenge, just because it's the politically correct thing to do, right?

Airman: Right, but it should be pretty easy to figure out what the mission requirements are and what kinds of differences we need to encourage and discourage. I know my job and what it takes to get it done, so I think I could figure this out.

Researcher: You probably can, if you're willing to be brutally honest and objective. But our environment is continually changing and identifying requirements is likely to get more complex in the future. Two things will continue to challenge us as we think about mission requirements and what differences are compatible or incompatible. The first is technological, 
political or organizational changes in our mission, which might cause changes in non-negotiable requirements. ${ }^{3}$ For instance, we could use pilots who've been medically disqualified from flying to pilot our unmanned aerial vehicles. What was non-negotiable for a manned aircraft might be irrelevant for an unmanned one. We'll need to constantly evaluate our standards in light of mission changes.

The second thing that will challenge our ideas about non-negotiable requirements is external changes in social attitudes or policies. ${ }^{4}$ Consider for instance, the growing pressure to include homosexuals in the military. Is homosexuality really prejudicial to good order and discipline, or are we just acting on a preference not to be around people we perceive as immoral or different? I don't have the answer to this question; I only ask it because it illustrates the importance of thinking about mission requirements before you negatively judge a person who is different. The

DOD believes there is a mission reason for excluding homosexuals and the Supreme Court continues to support this decision. ${ }^{5}$ However, there is growing public disagreement with this position and our credibility depends on continually ensuring our rationale is mission-based.

This is a very perplexing problem for the military, probably as difficult as the integration of blacks and women was in the past. Regardless of whether homosexuals are ultimately included or excluded, the only way we'll be able to resolve this issue satisfactorily is to focus on the nonnegotiable requirements, articulate them successfully to all airmen and the American people, and insist on absolute consistency in how we respond to this difference.

\section{What does this conversation mean to planners?}

This conversation is about how we determine what are acceptable and unacceptable differences and how we respond to these differences. Without a clear and consistent process for evaluating differences, all airmen are at the whim of supervisor interpretation and the potential 
for unfairness is high. Knowing this, airmen are unlikely to trust diversity management and engage in the openness it requires.

It's easy to say that we will draw the line at the point of mission requirements, but much tougher to do. It might appear a matter of simple logic to determine what mission requirements are, but the reality is unlikely to be an antiseptic process. ${ }^{6}$ The issue of homosexuality shows us just a few likely responses to this kind of examination. Ask an airman what they think about homosexuals in the military and you will get impassioned statements of personal ethics and morality, defenses of the warrior brotherhood, mingled with descriptions of life in the foxhole or tent. To avoid this emotion, planners must spend considerable time researching and teaching the differences between mission, culture and preference. They must facilitate organization-wide consideration of these issues, so that we can establish clear guidelines enabling every airman to know where we draw the line on acceptable or unacceptable differences. ${ }^{7}$

Second, planners need to determine how the Air Force will respond to differences. Assuming we use something like Thomas' three-pronged approach, how would we currently respond, and what are the challenges for planners? With regard to excluding unacceptable differences the Air Force is in good shape. We have a well-developed system of correction, punishment and discharge, with sufficient oversight to ensure fairness. The task for planners is to ensure clear understanding of the definition of unacceptable difference, so that the system remains fair.

How would airmen do at simply accepting behaviors which are different, but which have no mission impact? This is a difficult behavior for any person. It's possible that this might be even more difficult for airman, because our culture is more conservative, decisive and dominant. ${ }^{8}$ We are simply not an organization that lets things go. Planners need to carefully understand airman 
abilities (or lack thereof) to accept diverse attributes, then develop training, education and development programs to establish this as a desirable personal skill.

And finally, how will airman affirm and leverage the differences that can improve mission productivity? By and large, this comes down to one-on-one interaction. ${ }^{9}$ Each airman must understand the strengths of everyone else on his or her team, then find a way to bring those strengths into the fore. It's as simple as dealing with the older gentleman in our earlier conversation. Simple, but not easy. We've already discussed the need for extensive training in the kinds of personal skills this will require. Additionally, planners need to consider how the personnel system is structured in terms of diversity management. Vice Admiral Tracy makes a compelling case for the idea that personnel systems must become more responsive to individuals and tailorable to particular situations and needs. She also acknowledges how extraordinarily difficult this would be for the military to accomplish. ${ }^{10}$ However, diversity management can't completely flourish within a rigid personnel system that isn't able to utilize and reward airman based on individual differences.

\section{Notes}

${ }^{1}$ Thomas and Woodruff, 32.

2 Thomas and Woodruff, 32. To explain this, they use Phil Jackson's approach to managing Dennis Rodman. “...he affirmed the player's ability to deliver double-digit rebounds (necessary for mission accomplishment), remained publicly noncommittal about his extracurricular activities (no impact on mission), and discouraged behaviors that got him ejected from the game at the expense of his teammates (degrades the mission)." (Parens inserted by this author).

${ }^{3}$ Thomas and Woodruff, 219.

${ }^{4}$ Ibid.

5 Jennings Moss, “Pentagon Clarifies Gays Policy: 'Don't Ask, Don't Tell Revisions Intended to End Abuses." ABCNEWS.Com, 13 August 1999. On-line. Internet, 14 December 1999. Available from http://www.abcnews.go.com/sections/us/DailyNews/militarygays 990813.html

${ }^{6}$ Thomas and Woodruff,

${ }^{7}$ This author believes the exclusion of homosexuals is problematic for other minorities as well. Much of the conventional wisdom for excluding homosexuals could apply to the exclusion of females or ethnic minority groups. Minority members hear the message, "We don't want 


\section{Notes}

homosexuals, because we don't like what they are and it would be impossible to work with them," and wonder, "is that what white military men think about me?" Minority members might also reason that if the DOD was not acting based on requirements when it excluded them in the past, it might also not be acting on requirements when it excludes homosexuals. The DOD must articulate and ensure understanding of a requirements-based reason for excluding homosexuals, that differentiates homosexuality from other different behaviors-not only to convince the public, but to assure its minority members that it isn't hypocritical with regards to its fairness message. If it can't do this, the logical conclusion is that the DOD is wrong about one of two things: including women and ethnic minorities or excluding homosexuals.

${ }^{8}$ Heather Dryburgh, "Work Hard, Play Hard," Gender and Society 13, no. 5 (October 1999): 664-682; Business Management Practices, on-line, Firstsearch, 12 November, n.p. Dryburgh found that in a dominant culture, the minority tends to adopt majority behaviors and values in an attempt to fit in and be more successful. This, in effect, reinforces the right of the majority to insist on assimilation, and in this author's opinion makes it increasingly difficult for the majority to understand why or how it should tolerate differences. Thomas E. Ricks, "The Widening Gap Between the Military and Society," Atlantic Monthly, July 1997, excerpt from Making the Corps, Scribner, 1997, in Leadership and Command Phase 1 Coursebook, Academic Year 2000, Air Command and Staff College, 39-49. Ricks describes the double-edged sword of a strong military culture and a sense of alienation from, and superiority to, civilian society. If Ricks' description is accurate, then the growing diversity of the Air Force is likely to be viewed by the majority as an onslaught of problems to be erradicated, rather than an opportunity. Again, this doesn't bode well for the ability of military members to be accepting of diversity.

${ }^{9}$ Thomas and Woodruff,

${ }^{10}$ Tracy, n.p. 


\section{Part 6}

\section{Conclusions: Let's talk about what's left to talk about}

This report discussed four of the likely barriers to diversity management: failure to talk about discrimination and the relationship of fairness programs to diversity management, failure to clearly define sameness and difference, failure to deal with the legacy of Affirmative Action, and failure to set appropriate limits on diverse behavior.

Planners have a big task ahead if they wish to overcome these barriers. At a minimum, they must be brutally honest about where the Air Force stands with regard to discrimination and fairness and consider how past diversity efforts may affect diversity management. They must be able to define in a simple but descriptive way what diversity is and why we need diversity management. Finally, they must be able to define a clear basis for using or rejecting diverse behaviors.

This research wasn't intended as an argument against implementing diversity management. Rather, it was intended to help planners enter into diversity management with eyes wide open so they will plan more successfully. To completely inform this planning process, some additional study is needed. We need to validate the relevance of these theoretical barriers to the Air Force population. This author intended to develop the information in this paper into a survey instrument, which could be presented to Air University students or other Air Force groups. This 
wasn't feasible within the time and length constraints of this project, but would be a logical endeavor for an Air University student in the future.

We need to understand the kinds of forces that might work with equal strength in favor of implementing diversity management and determine which of those forces are already present in the Air Force. For instance, there is some debate in the literature as to whether "Generation X" may be more tolerant of diversity than previous generations. ${ }^{1}$ If this is true, implementing diversity management might be a matter of understanding and leveraging the culture of our younger troops. Additionally, much of good diversity management is simply good leadership and commitment to change. The Air Force has a strong cultural value for leadership, and extensive formal and informal leadership training and development programs. This infrastructure could be a powerful tool to enhance implementation of diversity management.

Finally, the Air Force already possesses considerable information about its internal environment in the form of data from unit climate assessments and other similar surveys. Properly evaluated, this information might yield a wealth of data about the internal environment. Additionally, unit climate assessments could be restructured to specifically collect information about airman resistance to or support for diversity management.

At some point, the studying ends and the action begins. The overwhelming opinion in the literature is that this action shouldn't start without complete commitment from senior leadership. It also seems obvious that we should approach this with a long-term perspective-if over 50 years of legally mandated fairness programs haven't entirely overcome bad human behavior, why should we expect diversity management to be an overnight success? So it appears that if we want diversity management, we must gird for a protracted battle. 
Thomas offers a dissenting opinion about how to embark on diversity management that is more along the lines of guerilla warfare. It serves as both final food for thought and a challenge to good leaders:

In the past, most of us concluded that dealing with something as complicated as diversity should be left to the managers and owners. We kept quiet about our own feelings, waiting for the bosses to figure out the company's official position. We were wrong....True diversity management begins and ends with individuals. It begins with each of us accepting our responsibility as actors in the diversity scenario, and it ends with our acquiring certain specific skills and achieving a level of maturity in our thinking and acting about diversity. ${ }^{2}$

\section{Notes}

${ }^{1}$ Bobo, n.p.

${ }^{2}$ Thomas and Woodruff, 8-9. 


\section{Bibliography}

Air Force Instruction (AFI) 36-2706, Military Equal Opportunity and Treatment Program, December 1996.

Air Force Pamphlet (AFPAM) 36-2705. Discrimination and Sexual Harassment, February 1995.

Asseo, Laurie. 'Court Upholds Gay Policy: No Change in Military's 'Don't Ask, Don't Tell'

Practice. ABCNEWS.com, 11 January 1999, n.p. On-line. Internet, 14 December 1999. Available from

http://www.abcnews.go.com/sections/us/DailyNews/gaymilitary990111.html.

Bobo, Lawrence. "Race, Interests, and Beliefs About Affirmative Action: Unanswered Questions and New Directions." American Behavioral Scientist 41, no. 7 (April 1998): n.p. Academic Search Elite. On-line. EBSCOHost, 26 November 1999.

Bond, Meg A. and Jean L. Pyle. "Diversity Dilemmas at Work." Journal of Management Inquiry 7, no. 3 (September 1998): n.p. Academic Search Elite. On-line. EBSCOHost, 14 November 1999.

Capowski, Genevieve. "Can't See the Diversity for all the Differences." HR Focus 75, no. 7 (July 1998): 16. Academic Search Elite. On-line. EBSCOHost, 12 November 1999.

Catalystwomen.org. "Women of Color Report a 'Concrete Ceiling' Barring Their Advancement." On-line. Internet, 21 November 1999. Available from http://www.catalystwomen.org/press/mediakit/release071399woc.html.

Cummings, Thomas G., and Christopher G. Worley. Organization Development and Change. $5^{\text {th }}$ Ed. Minneapolis-St. Paul: West Publishing Company, 1993.

Dass, Parshotam and Barbara Parker. "Strategies for Managing Human Resource Diversity: From Resistance to Learning." Academy of Management Executives 13, no. 2 (1999): 68-80.

Digh, Patricia. "Coming to Terms with Diversity." HRMagazine 43, no. 12 (1998): 117-120.

Digh, Patricia. "Developing a Diversity Statement." Association Management 51, no. 2 (1999): 53-55. Business Management Practices. On-line. Firstsearch, 24 October 1999.

Diversity Training Group. "Dynamic Demographics." On-line. Internet, 12 October 1999. Available from http://www.diversitydtg.com/articles/demogs.html

Dryburgh, Heather. "Work Hard, Play Hard." Gender and Society 13, no. 5 (October 1999): 664682. Business Management Practices. On-line. Firstsearch, 12 November.

Fisher, Anne. "Are You Being Held Back By Discrimination?" Fortune 140, no.4, (16 August 1999): 186. Academic Search Elite. On-line. EBSCOHost, 14 November 1999.

Flynn, Gillian. "The Harsh Reality of Diversity Programs.” Workforce 77, no. 12 (1998): 26-32. Business Management Practices. On-line. Firstsearch, 24 October 1999. 
Flynn, Gillian. "White Males See Diversity's Other Side.” Workforce 78, no. 2 (February 1999): 52-56. Academic Search Elite. On-line. EBSCOHost, 12 November 1999. .

Frost, Delyte D. "Review Worst Diversity Practices to Learn from Worst Diversity Practices to Learn From Others' Mistakes." HR Focus 76, no. 3 (April 1999): 11-12. Academic Search Elite. On-line. EBSCOHost, 12 November 1999.

Gandy, Jr., Oscar H. and Jonathan Baron. "Inequality: It's All In The Way You Look At It." Communication Research 225, no. 5 (October 1998): 505-525. Academic Search Elite. Online. EBSCOHost, 26 November 1999.

Garramone, Jim. "Survey Examines Race Relations in Military." American Forces Press Service, 23 November 1999. On-line. Internet, 26 November 1999. Available from http://www.defenselink.mil/news/Nov1999/n11231999_9911231.html

Hartwig, Robert. "Truth Can be Stranger than Fiction in Employment Practices Liability Arena." National Underwriter Property and Casualty 103, no. 23 (1999): 25, 27. Business Management Practices. On-line. FirstSearch, 24 October 1999.

Hood-Phillips, Ray. "Embracing Racial Diversity: A Matter of Survival." Community College Week 11, no. 24 (12 July 1999): 4-5. Academic Search Elite. On-line. EBSCOHost, 14 November 1999.

Hughes, Richard L., Robert C Ginnett, and Gordan J. Curphy. Leadership: Enhancing the Lessons of Experience. Boston: Irwin, 1993.

Jehn, Karen A. "A Multimethod Examination of the Benefits and Detriments of Intragroup Conflict." Administrative Science Quarterly 40, no. 2 (June 1995): 256-282. Academic Search Elite. On-line. EBSCOHost, 22 November 1999.

Jehn, Karen A., and Clint Chadwick et al. "To Agree or not to Agree: The Effects of Value Congruence, Individual Demographic Dissimilarity, and Conflict on Workgroup Outcomes." International Journal of Conflict Management 8, no. 4 (October 1997): 287-305. Academic Search Elite. On-line. EBSCOHost, 22 November 1999.

Jones, DeEtta. "The Definition of Diversity: Two views. A More Inclusive Definition." Journal of Library Administration 27, no. 1/2 (1999): 5-15.

Knouse, Stephen B., and Mickey R. Dansby. "Percentage of Work-Group Diversity and WorkGroup Effectiveness." Journal of Psychology Interdisciplinary and Applied 133, no. 5 (September 1999): 486-494. Business Management Practices. On-line, FirstSearch, 12 November 1999.

Lippman, Helen. "Harnessing the Power of Diversity." Business and Health 17, no. 6 (June 1999); 40.

Maio, Gregory R., and Victoria M. Esses. "The Social Consequences of Affirmative Action: Deleterious Effects on Perceptions of Groups." Personality and Social Psychology 24, no. 1 (January 1998): 65-74. Academic Search Elite. On-line. EBSCOHost, 26 November 1999.

McLeod, Poppy Lauretta, and Sharon Alisa Lobel. "Ethnic Diversity and Creativity in Small Groups.” Small Group Research 27, no. 2 (May 1996): 248-264. Academic Search Elite. On-line. EBSCOHost, 22 November 1999. 
Milkovich, George T., and John W. Boudreau. Human Resource Management. $6^{\text {th }}$ ed. Homewood, IL: Irwin, 1991.

Moss, Jennings. "Pentagon Clarifies Gays Policy: 'Don't Ask, Don't Tell Revisions Intended to End Abuses.” ABCNEWS.Com, 13 August 1999. On-line. Internet, 14 December 1999. Available from http://www.abcnews.go.com/sections/us/DailyNews/militarygays990813.html.

Myers, Laura. "Group Says Harassment Rising: Gay Rights Group Criticizes Pentagon." The Associated Press, 15 March 1999. On-line. Internet, 14 December 1999. Available from http://www.abcnews.go.com/sections/us/DailyNews/military90315.html.

Newton, Lloyd W. "America's Armed Forces, America's Diversity." Remarks to the symposium commemorating the $50^{\text {th }}$ Anniversary of Executive Order 9981, University of Texas Alumni Center, Austin. April 15, 1998; on-line, Internet, 16 January 2000. Available from http://www.af.mil/news/speech/current/Americas_Armed_Forces_Ame.html.

Pearce, John A. II, and Richard B. Robinson, Jr. Strategic management: Formulation, Implementation, and Control. $5^{\text {th }}$ Edition. Burr Ridge, Illinois: Irwin, 1994.

Pelled, Lisa H., Kathleen M. Eisenhardt, et al. "Exploring the Black Box: An Analysis of Work Group Diversity, Conflict and Performance." Administrative Science Quarterly 44, no. 1 (March 1999, 1-28. Academic Search Elite. On-line. EBSCOHost, 24 October 1999.

Peterson, Lorna. "The Definition of Diversity: Two Views. A More Specific Definition." Journal of Library Administration 27, no. 1/2 (1999): 17-26.

Ricks, Thomas E. "The Widening Gap Between the Military and Society." Atlantic Monthly, July 1997, Excerpt from Making the Corps, Scribner, 1997. In Leadership and Command Phase 1 Coursebook, Academic Year 2000, Air Command and Staff College. 39-49.

Rodriguez, Ralph A. "Challenging Demographic Reductionism." Small Group Research 29, no. 6 (December 1998): 744-758. Business Management Practices. On-line. First Search, 12 November 1999.

Smith, Anna. “Gender Defender.” Management 46, no. 4 (May 1999): 20-22. Academic Search Elite. On-line, EBSCOHost, 19 March 2000.

Thomas, David A., and Robin J. Ely. "Making Differences Matter: A New Paradigm for Managing Diversity." Harvard Business Review 74, no. 5 (September/October 1996): 79-90. Academic Search Elite. On-line, EBSCOHost, 26 November 1999.

Thomas, David C. "Cultural Diversity and Work Group Effectiveness." Journal of CrossCultural Psychology 30, no. 2 (March 1999): 242-263. Academic Search Elite. On-line. EBSCOHost, 24 October 1999.

Thomas, R. Roosevelt Thomas, Jr., and Marjorie I Woodruff. Building a House for Diversity: How a fable about a Giraffe and an Elephant offers new strategies for today's workforce. New York: AMACOM, 1999.

Tracey, Vice Admiral P.A.. "The Case for Agility-Adapting Military Human Resources to a Changing World." Lecture Slides. Air Command and Staff College, Maxwell Air Force Base, Alabama, January 2000. 
US Department of Defense. Armed Forces Equal Opportunity Survey. Washington, D.C.: Office of the Secretary of Defense, November 1999. On-line. Internet, 26 November 1999. Available from http://www.defenselink.mil/news/Nov1999/b112231999_bt544.html.

US Department of Defense. Career progression of Minority and Women Officers. Washington, D. C.: Office of the Under Secretary of Defense (Personnel and Readiness), November 1999. On-line. Internet, 26 November 1999. Available from http://www.dticaw.dtic.mil/prhome/careerprog.html

Widnall, Sheila E., Secretary of the Air Force. "Setting the Example of Air Force Leadership Through Diversity." Address. Strength Through Diversity Conference, United States Air Force Academy, Colorado, April 1995, 6; on-line, Internet, 16 January 2000, available from http://www.af.mil/news/speech/current/Setting_the_Example_of_Air_.html.

Widnall, Sheila E., Secretary of the Air Force. "Defense Advisory Committee on Women in the Service." Address. DACOWITS Spring Conference, Vienna, Virginia, 27 April 1995, 5; on-line, Internet, 16 January 2000, available from

http://www.af.mil/news/speech/current/Defense_Advisory_Committee.html 